\title{
Teedia lucida ROOT EXTRACTS BY ULTRASONICATION AND MACERATION TECHNIQUES: PHYTOCHEMICAL SCREENING, ANTIMICROBIAL AND ANTIOXIDANT POTENTIALS
}

\author{
P.T. Motsumi ${ }^{1}$, T. Qwebani-Ogunleye ${ }^{2}$, I.P. Ejidike ${ }^{1,3, *}$, F.M. Mtunzi ${ }^{1,2}$ \\ and $Z$. Nate ${ }^{1}$ \\ ${ }^{1}$ Department of Chemistry, Vaal University of Technology, Private Bag X021, Vanderbijlpark, \\ 1911, South Africa. \\ ${ }^{2}$ Institute of Traditional Knowledge and Traditional Medicine, Vaal University of Technology \\ Southern Gauteng Science and Technology Park, Sebokeng, 1983, South Africa. \\ ${ }^{3}$ Department of Chemical Sciences, Anchor University, Lagos, Nigeria. \\ *E-mail: iejidike@aul.edu.ng; destinedchild12@gmail.com
}

ABSTRACT

Medicinal plants have been used for medicinal purposes as antibiotics and anti-inflammatory agents in times memorial in most parts of Southern Africa. The study focused on the phytochemical screening, in-vitro examination of antioxidant and antimicrobial potentials of Teedia lucida root extracts in different solvents like methanol, acetone, water, and dichloromethane. The phytochemical investigation of the solvent extracts as a result of two extraction methods: ultrasonication and maceration, revealed the presence of secondary metabolites in the extracts. The total phenols and flavonoids contents varied from 270.801-932.582 GAE mg/g and 160-345.56 QE mg/g in the extract powders respectively. Radical Scavenging Activity (RSA) of the solvent extracts against DPPH radical and quercetin as positive control revealed that dichloromethane extracts by ultrasonication method exhibited 10.28$66.36 \%$ DPPH scavenging potentials. The antimicrobial activity of methanolic extract possesses MIC values $(0.3195$ and $0.639 \mu \mathrm{g} / \mathrm{ml})$, acetone $(0.3968$ and $0.792 \mu \mathrm{g} / \mathrm{ml})$ by ultrasonication method against $S$. aureus and $S$. sonnei strains respectively. In conclusion, the study demonstrates that different solvent root extracts of T. Lucida contain constituents with antioxidant and antibacterial potentials.

Keywords: Teedia lucida, Phenolic, Roots, Tannins, Total Flavonoids, Antioxidant, Antibacterial

(C) RASĀYAN. All rights reserved

\section{INTRODUCTION}

The global community has come to grasp the usage of herbs for therapeutic purposes, and their uses in traditional medicine practices have entrenched in several cultural practices throughout the developing countries. ${ }^{1-4}$ WHO estimated that $80 \%$ of the world's populace currently uses herbs for some aspect of healing purposes and disease control. ${ }^{5,6}$ WHO have also recorded that of 119 plant-derived pharmacological agents, about seventy-four percent are found useful in modern medication in ways that relate directly with their traditional usage as herbal remedies by native cultures. ${ }^{5,7-9}$ Currently, significant pharmaceutical companies are presently involved with wide-ranging research on plant and herbs collected from the sub-Sahara, rain forests and other places for their possible medicinal values. Treatment of obesity, cancer, diabetes, drug addiction, and other ailments has benefitted directly and indirectly from African traditional pharmacologists through plants such as African willow, hoodia, iboga and others. $^{7,8,10,11}$

The effectiveness of numerous therapeutic plants has been authenticated by scientists and professionals, from Europe to Africa. Many of the recent research validating folk medicine with respect to herbs have

Rasayan J. Chem., 13(1), 423-433(2020)

http://dx.doi.org/10.31788/RJC.2020.1315594

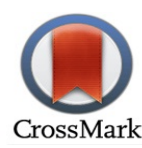


RASĀYAN J. Chem.

Vol. 13 | No. 1 |423 - 433| January - March | 2020

been conducted in China, India, Germany, Taiwan, Japan, Russia and recently in Botswana, Nigeria, Swaziland and South Africa. ${ }^{6,12}$ Meanwhile, the cultivation of medicinal plants will help restore the preservation and indigenous knowledge indigenous plant medicine consumers. This population has increased the demand for medicinal plants as a result of indigenous cultivation knowledge degeneration.

The structure of bioactive compounds in medicinal plants differs, some compounds belonging to a class of compounds including alkaloids, peptides, coumarins/chromones, terpenoids, and phenols. ${ }^{6,13}$ The plants from Scrophulariceae family are widely known for their traditional medicinal usage. The aerial parts of these plants are often used for diagnosis of inflammation, menstrual disorders, hypertension, and diarrhea while the roots of these plants showed antibacterial and antioxidant properties. ${ }^{2}$ Scrophulariceae and other plants indicate the presence of secondary metabolites possessing activities different functions within the plant. Most secondary metabolites found in plants are phenolic compounds, and almost 200000 therapeutic compounds had been identified in plants. ${ }^{13,14}$

Scrophulariceae Teedia Lucida (Stinkbos), found in mountainous and flat regions, is a plant made of green leaves and purple/pink flowers. Over the years, people have learned to adapt to the conditions of using plants as health remedies. ${ }^{7,8,14,15}$ However, because of the poor level of sanitation and hygiene, there has been high exposure of the populace to infections from micro-organisms like bacteria, fungus, and virus; this has lead to chronic diseases resulting from the use of medicinal plants. Previous studies on the medicinal plant have shown that phenolic compounds exhibit redox properties, thus antioxidant activity. Some phenolic compounds can donate a proton to or share an electron with the free radical species like reactive oxygen species (ROS) and reactive nitrogen species (RNS). They are also called singlet oxygen quenchers. $^{16,17}$

In this study, root parts of T. Lucida plant were studied for scientific authentication and validation because there is no much information about the plant parts. Phytochemicals from T. Lucida root extracts in methanol, dichloromethane, acetone, and water employing ultrasonication, maceration, and decoction were evaluated. The in-vitro antioxidant and antibacterial potential alongside the total phenol contents and total flavonoids contents of the solvent extracts were also investigated.

\section{EXPERIMENTAL}

\section{Equipment and Chemicals}

UV-Vis Spectrometer (T80+, PG Instruments LTD, China), Thin Layer Chromatography (Merck, silica gel 60, $\mathrm{F}_{254}$, Germany), 5.7 L Ultrasonic Bath with timer function (703, Scientec, South Africa), Mechanical Shaker (SPO-MPB, Labcon Laboratory Equipment, South Africa), di-ionized water, Methanol, Acetone, Dichloromethane, Aluminium chloride, FCR, Vanillin, and DPPH were obtained from Merck and Aldrich-Sigma (Johannesburg, South Africa).

\section{Plant Material Selection And Treatment}

The plant roots of Teedia Lucida collected were air-dried after washing in the dark, and milled into a fine powder using a Lasec Polymix PX-MFC 90D crusher. The sample was stored in the dark at room temperature for additional examination. Five grams of the finely powdered plant material were transferred into a beaker and $250 \mathrm{ml}$ of different solvents namely acetone, methanol, water and dichloromethane, were added in separate beakers. The water mixture was heated on a hot plate with continuous stirring at $30-40{ }^{\circ} \mathrm{C}$ for 20 min. $^{18-20}$ The methanol, acetone, and dichloromethane mixtures were macerated and another set ultrasonicated. The individual solvent extracts were sieved through filter (Whatman filter No 1) paper; then the filtrates were allowed to evaporate to dryness in extraction fume for further analysis. Extraction mass yield was determined using Equation (1):

$$
\text { Percentage }(\%) \text { Yield }=\frac{\text { Final weigh of extract }(g)}{\text { Initial weight of plant material }(g)} \times 100
$$

\section{Thin-layer Chromatography (TLC) Analysis}

The chemical screening of the Teedia Lucida root ultrasonication assisted and maceration assisted extraction methods were performed using aluminum-backed TLC resources (silica gel 60, $\mathrm{F}_{254}$ ). The extracts from the two extraction methods such as ultrasonication and maceration assisted were re- 
RASĀYAN J. Chem.

Vol. 13 | No. 1 |423 - 433| January - March | 2020

dissolved before analyzing the plates spotted with the different plant extracts. The plates were then established in unlike solvent tank arrangements of ethyl acetate: methanol: water (EMW, 30:4.05:3, v/v/v) and chloroform: ethyl acetate: formic acid (CEF, 30:24:6, v/v/v). Saturation of the tank was allowed with the eluent for 24 hours before inserting the plate inside to develop the chromatogram. Application of the extracts carried out swiftly and developed with no postponement to reduce the likelihood of constituent's oxidation or photo-oxidation. The developed plates under UV light at wavelength: 254 and $365 \mathrm{~nm}$ were then visualized in order to detect UV absorbing or fluorescing bands. Then after, the plates were further sprayed with vanillin reagent obtained by liquifying $0.1 \mathrm{~g}$ of vanillin (Aldrich-Sigma) in methanol of about $28 \mathrm{ml}, 1 \mathrm{ml}$ of $\mathrm{H}_{2} \mathrm{SO}_{4}$ and boiled at $110{ }^{\circ} \mathrm{C}$ for $45 \mathrm{sec}$ for ideal color change. ${ }^{6,21}$

\section{Qualitative Phytochemical Tests}

Profiling and documentation of bioactive biochemical constituents in the extracts were screened using the standard measures with little modifications. The test carried out include the following: flavonoids, phenols, carbohydrates, saponins, and proteins. ${ }^{2,6,7,22}$

\section{Fehling's Test For Sugars}

Individual solvent extracts were dissolved in $5 \mathrm{ml}$ distilled water each and filtered. This was followed by hydrolysis of the filtrates with dilute hydrochloric acid $(\mathrm{HCl})$, and then neutralized with alkali, the resulting mixtures were then boiled with solutions of Fehling's A and B. Development of a red precipitate signposts the existence of reducing sugars.

\section{Test for Saponins}

$0.5 \mathrm{~g}$ of extracts was shaken with $2 \mathrm{ml}$ of distilled water and vigorously shaken well for $20 \mathrm{~min}$ in a graduated cylinder. The appearance of a $1 \mathrm{~cm}$ layer of foam signposts the existence of saponins.

\section{Ferric Chloride Test For Flavonoids}

To $2 \mathrm{ml}$ of the extracts, about 5 drops of a solution of ferric chloride (10\%) were added. The colour change to green-blue is a suggestion of the presence of a phenolic hydroxyl group.

\section{Ellagic Test For Phenols}

$2 \mathrm{ml}$ of extract filtrates were reacted with four drops of glacial acetic acid $5 \%(\mathrm{w} / \mathrm{v})$, followed by four droplets of $5 \%(\mathrm{w} / \mathrm{v}) \mathrm{NaNO}_{2}$ solution. The combinations were allowed to stand after shaking for $5 \mathrm{~min}$. The appearance of a muddy brown precipitate designates the occurrence of phenols.

\section{Xanthoproteic Test For Proteins}

To individual extract, a few drops of conc. nitric acid $\left(\mathrm{HNO}_{3}\right)$ was added. The formation of light-yellow coloration is an indication of protein presence.

\section{Quantitative Phytochemical Tests \\ Total Flavonoids Determination}

The aluminum(III) chloride colorimetric method with some modification was followed. ${ }^{6,16,23}$ Teedia Lucida root extracts $(3 \mathrm{ml})$ of different solvent (methanol, acetone, and dichloromethane) in different test tubes were mixed with methanol $(3 \mathrm{ml}), 10 \%$ aluminum chloride $(0.2 \mathrm{ml}), 1 \mathrm{M}$ potassium acetate $(0.2$ $\mathrm{ml})$ and distilled water $(5.6 \mathrm{ml})$. The mixtures were allowed to stand at room temperature for $30 \mathrm{~min}$. The absorbance measured at $420 \mathrm{~nm}$. Preparation of the calibration curve was achieved using quercetin concentrations $(5-150 \mathrm{mg} / \mathrm{ml})$ dissolved with methanol. The flavonoids contents were expressed in terms of quercetin equivalent ( $\mathrm{mg} \mathrm{QE} / \mathrm{g})$.

\section{Determination of Total Phenols}

The determination of phenol content was carried out using the Folin Ciocalteu reagent method. ${ }^{6,23} 1 \mathrm{ml}$ of the root extracts were mixed with Folin Ciocalteu reagent $(0.5 \mathrm{ml})$, then $1.5 \mathrm{ml}$ of saturated $\mathrm{Na}_{2} \mathrm{CO}_{3}(3 \mathrm{~g}$ in water $50 \mathrm{ml}$ ) was introduced into the mixture and allowed to stand at room temperature for $30 \mathrm{~min}$ in the dark. The absorbance for the solutions was collected using UV-spectrophotometer at a constant 


\section{RASĀYAN J. Chem. \\ Vol. 13 | No. 1 |423 - 433| January - March | 2020}

wavelength of $725 \mathrm{~nm}$ (T80+, PG Instruments Ltd). The calibration curve was obtained by preparing working standards: gallic acid $(30-210 \mathrm{mg} / \mathrm{ml})$ solution in distilled water. Then extracts were analyzed after $30 \mathrm{~min}$, and total phenol values expressed in terms of gallic acid equivalent (mg GAE/g of root material).

\section{Minimum Inhibitory Concentration (MIC) of Antibacterial Activity Analysis}

Minimum Inhibitory Concentration of the methanol, acetone and dichloromethane Teedia Lucida root extracts for antibacterial activity was evaluated by Microdilution bioassay. Gram-positive (Staphylococcus aureus, ATCC 25923) and Gram-negative (Shingella Sonnei, ATCC 22371) bacterial strains that was previously cultured overnight (incubated at $37^{\circ} \mathrm{C}$ in a water bath with an orbital shaker), were diluted with sterile Mueller-Hinton (MH) broth to give final fresh inocula of approximately $10^{6}$ $\mathrm{CFU} / \mathrm{ml}$ (colony forming units). One hundred microliter of each plant extracts were sequentially diluted two-fold with sterile distilled water in a 96-well microliter plate for each of the two bacterial strains. 0.1 $\mathrm{mg} / \mathrm{ml}$ Neomycin (Sigma-Aldrich, Germany), a two-fold dilution was utilized as a positive control against the individual bacterium. 100 microliters of each bacterial culture were added to each well. Distilled water was used as a negative control. Thereafter, plates were sheltered with Para-film and incubated for $24 \mathrm{hrs}$ at $37{ }^{\circ} \mathrm{C}$. The addition of $30 \mu \mathrm{l}$ of $0.2 \mathrm{mg} / \mathrm{ml} p$-iodonitrotetrazolium chloride (INT) (SigmaAldrich, South Africa) indicated the presence of bacterial growth, with a further incubation for $24 \mathrm{hrs}$ at $37^{\circ} \mathrm{C}$. The colorless tetrazolium salt when biologically reduced to a red product indicates the presence of active organisms, and the MIC values determined as the concentration in the latter wells with no colour change detected after the addition of INT indicator. A reddish-pink colour was used as a signpost for bacterial growth in the wells. All assessments were carried out in triplicate, and the antimicrobial potentials expressed as the mean of inhibition. ${ }^{24,25}$

\section{DPPH-Radical Scavenging Activity}

DPPH radical scavenging capacity of Teedia Lucida root extracts was studied. The radical possess a maximum absorption at $517 \mathrm{~nm}$, whose initial colour intensity decreased in the presence of an antioxidant compound available in plant extracts. A decrease in mixture absorbance indicates the radical scavenging activity of the test samples being evaluated. In this study, $3 \mathrm{ml}$ DPPH solution in methanol $(2.0 \mathrm{mg} / \mathrm{ml})$ was added to $1 \mathrm{ml}$ of methanol, acetone, dichloromethane solutions of the plant root extracts containing the following $(0.2,0.4,0.6,0.8,1.0 \mathrm{mg} / \mathrm{ml})$ concentrations. The sample mixtures were permitted to incubate at room temperature for $30 \mathrm{~min}$ in the dark environment, and then the decrease in absorbance at $517 \mathrm{~nm}$ was spectrophotometrically measured. The experiment was carried out in triplicate.

\section{Statistical Analysis}

To ensure reproducibility, all experiments were completed in triplicate. The concentration of each portion was found from the calibration functions of each replicate, and the results obtained were conveyed as mean \pm standard deviation (mean $\pm \mathrm{SD}), \mathrm{n}=3$.

\section{The Yield of Crude Extracts}

\section{RESULTS AND DISCUSSION}

This study revealed the existence of secondary metabolites in the various Teedia Lucida plant extracts as a result of different masses owing to the different solvents and methods of extraction (\% Yield). Results obtained showed a trend in percentage yield (Table-1) as follows: Methanol > Acetone > Dichloromethane. A closely related phenomenon was observed as revealed by Tiwari et al. (2011), divulging that methanol (alcohols) extracts more efficiently than acetone, and this observation was fashioned by the polarity of the solvent and metabolites interactions. The trend in solvent polarities can be ranged as follows: Methanol $>$ Acetone $>$ Dichloromethane, indicating that the majority of present secondary metabolites are polar constituents. It can be related that phenolic compounds are polar, as this fact is supported by literature revealing that within the plant kingdom, the majority of secondary metabolites are phenolic compounds. ${ }^{22}$ When comparing the two extraction methods: ultrasonication and maceration; ultrasonication method exhibited high yields (Table-1). This observation can be attributed to 
RASĀYAN J. Chem.

Vol. 13 | No. 1 | 423 - 433| January - March | 2020

the ultrasonic waves applied by the equipment forcing the cell walls to break, thereby enhancing the ease of phytochemicals extraction as reported by Vinatoru et $\mathrm{al}^{26}$

Table-1: Mass Yield of Different Solvent Extracts of Teedia Lucida Root Plant

\begin{tabular}{lllll}
\hline $\begin{array}{l}\text { Extraction } \\
\text { Solvents }\end{array}$ & $\begin{array}{l}\text { Extraction } \\
\text { Methods }\end{array}$ & Denotation & $\begin{array}{l}\text { Mass of Extract } \\
(\mathrm{g})\end{array}$ & $\begin{array}{l}\text { Yield } \\
(\%)\end{array}$ \\
\hline Methanol & Ultrasonication & MET-ultra & 0.4711 & 9.4100 \\
Methanol & Maceration & MET-mace & 0.4693 & 9.3661 \\
Acetone & Ultrasonication & ACE-ultra & 0.1485 & 2.9688 \\
Acetone & Maceration & ACE-mace & 0.1413 & 2.8215 \\
Dichloromethane & Ultrasonication & DCM-ultra & 0.1014 & 2.0059 \\
Dichloromethane & Maceration & DCM-mace & 0.0950 & 1.8890 \\
\hline
\end{tabular}

\section{Phytochemical Screening of Teedia Lucida Root Extracts Following Reagent Method}

Qualitative analysis of phytochemicals remains vital in plants medicinal and pharmacological studies. ${ }^{21,22}$ In this study, Teedia Lucida had demonstrated to contain secondary metabolites via the tests carried out using the reagent method. This method with plant extracts gave different colors or precipitation appearance, thereby indicating the presence of certain secondary compound (Tables-2 and 3) such as phenols, flavonoids, proteins, carbohydrates, and saponins. ${ }^{27}$ Methanol and acetone solvents were found to have extracted most of the bioactive constituents, while dichloromethane contained fewer compounds as compared to water. In the two methods, methanol extract showed no presence of saponins, while, dichloromethane showed no presence of phenols, flavonoids, and carbohydrates. When comparing the two methods of extraction, for example, water extracts by maceration methods contain fewer phytochemicals than water extracts by ultrasonication methods.

This observation could be elucidated by the context that maceration is not robust towards plant cell walls as compared to ultrasonication. In the maceration process, solvent washes the plant cell wall and a certain amount of solvent access the internal cell metabolites while ultrasonication gives room for temperature increase and vibrational frequencies within the sample environment aiding constant interaction between the plant cell wall and the solvent. The decoction method of water extracts demonstrated that the traditional medicinal method is intermediate as compare to maceration and ultrasonication when using water as an extract (Table-3).

Table-2: Phytochemical Screening of Teedia Lucida Root Extracts by Ultrasonication Method

\begin{tabular}{|c|c|c|c|c|c|}
\hline Compounds & Methanol & DCM & Water & Acetone & Water(Decoc) \\
\hline Phenols & + & - & + & + & + \\
\hline Flavonoids & + & - & + & + & + \\
\hline Proteins & + & + & - & + & - \\
\hline Saponins & - & + & + & + & + \\
\hline Carbohydrates & + & - & + & + & + \\
\hline
\end{tabular}

(+) presence of compound(s); (-) absence of compound(s); DCM- Dichloromethane

Table-3: Phytochemical Screening of Teedia Lucida Root Extracts by Maceration Method

\begin{tabular}{lcccc}
\hline Compounds & Methanol & DCM & Water & Acetone \\
\hline Phenols & + & - & + & + \\
Flavonoids & + & - & - & + \\
Proteins & + & + & - & - \\
Saponins & - & + & + & + \\
Carbohydrates & + & - & + & + \\
\hline
\end{tabular}

(+) presence of compound(s); (-) absence of compound(s); DCM- Dichloromethane

Among the plant metabolites, the largest and most abundant groups are compounds of phenolic, and their presence was found in the T. Lucida root extracts. ${ }^{14}$ The extract samples with phenolic and flavonoids compounds have been described to possess pharmacological properties such as antimicrobial, cardiovascular protection, antioxidant, antiatherosclerosis, anti-aging, anti-inflammatory and enhancement of endothelial function alongside the inhibition of cell proliferation and angiogenesis activities. ${ }^{13,21,25,28}$ Thus, the presence of phenol and flavonoids in the plant species signposts the medicinal potential of the plant. ${ }^{1,29,30}$ 
RASĀYAN J. Chem.

Vol. 13 | No. 1 |423 - 433| January - March | 2020

\section{Phytochemical Investigation of Crude Extracts By TLC-Vanillin-Sulphuric Acid}

Thin-Layer Chromatography (TLC) for phytochemical screening can be regarded as both qualitative as well as quantitative because of the number of bands representing various secondary plant compounds but this reason is less true because visible bands adhere to certain conditions such as polarity, visible light, dominance, thermolabile, UV light, and steric effects. ${ }^{21}$ Therefore, following this report, only those compounds adhering to visible light were observed. In this study, two mobile phase solvent systems were utilized for compound isolation of the different solvents extracts with respect to their polarities. Mobile phase systems include Ethyl acetate: Methanol: Water (EMW, 30:4.05:3); Chloroform: Ethyl acetate: Formic acid (CEF, 30:24:6). The mobile phase: EMW showed better separation than CEF. The advanced TLC plates were spurted with a solution of vanillin/ $\mathrm{H}_{2} \mathrm{SO}_{4}$, this was followed by heating at $100{ }^{\circ} \mathrm{C}$ to ensure the growth of color.

Separated constituents identification was attained based on the values of the retention factor $\left(\mathrm{R}_{\mathrm{f}}\right)$, as highlighted in Table-4. Separated compounds were visualized by natural color sight during the daylight or by fluorescent quenching on $254 \mathrm{~nm}$ (for extended $\pi$ electron systems or conjugated double bonds) or 366 nm. ${ }^{6,21}$ Different classes of compounds were detected, including flavonoids that are phenolic with a pinkish, yellow, or orange coloration. ${ }^{6,31}$ Different bands were observed in various solvent extracts by the two methods of extraction. The difference in band separation with respect to the solvent used, as shown in Table-4 displayed diverse $\mathrm{R}_{\mathrm{f}}$ values in a trend: methanol $>$ acetone $>$ dichloromethane. This can be attributed to the differences in secondary compounds polarity interacting differently with the (CEF and EMW) mobile phase of different ratios and silica stationary phase. Both methanol and acetone displayed several bands than dichloromethane, and this observation showcase the polarity of extractants significance since dichloromethane is a non-polar solvent.

Table-4: Retention Factors $\left(\mathrm{R}_{\mathrm{f}}\right)$ Bands of Different Compounds in Teedia Lucida Root in Different Solvent Systems

\begin{tabular}{llllll}
\hline $\begin{array}{l}\text { Solvent } \\
\text { Systems: }\end{array}$ & Ethyl Acetate: Methanol: Water (EMW) & \multicolumn{2}{l}{ Chloroform: Ethyl Acetate: Formic Acid (CEF) } \\
Extracts: & MET-mace & ACE-mace & MET-ultra & ACE-ultra & DCM-mace \\
\hline & 0.08 & 0.089 & 0.078 & 0.078 & 0.1 \\
& 0.12 & 0.12 & 0.17 & 0.17 & 0.225 \\
& 0.25 & 0.47 & 0.28 & 0.32 & 0.313 \\
& 0.32 & 0.5 & 0.32 & 0.39 & 0.35 \\
& 0.47 & 0.66 & 0.39 & 0.46 & 0.46 \\
& 0.57 & 0.73 & 0.46 & 0.48 & 0.65 \\
& 0.66 & 0.78 & 0.48 & 0.58 & 0.18 \\
\hline
\end{tabular}

Solvent systems: Ethyl acetate: Methanol: Water (EMW, 30:4.05:3); Chloroform: Ethyl acetate: Formic acid (CEF, 30:24:6)

Denotation: Methanol (ultra)- MET-ultra; Methanol (mace)- MET-mace; Acetone (ultra)- ACE-ultra; Acetone (mace)- ACEmace; Dichloromethane (mace)- DCM-mace; ultra- Ultrasonication; mace- Maceration.

\section{Determination of Phenols And Flavonoids In Teedia Lucida Extracts}

Phenolic compounds and flavonoids are the major compounds that impart the medicinal value of the plant and act as natural antioxidants. Total phenolic content in the present study was measured by the FolinCiocalteu reagent, which was expressed as mg gallic acid equivalents (GAE) per gram of plant material, while total flavonoid was investigated by aluminum(III) chloride colorimetric technique and articulated in terms of quercetin equivalent ( $\mathrm{mg} \mathrm{QE} / \mathrm{g}$ ). The results of total phenols and flavonoids were obtained using UV-vis spectroscopy. The instrument was calibrated, and the calibration curves (Figs.-1a and b) for phenols and flavonoids were obtained respectively. The standard curve equations and regression are (equation: $\mathrm{y}=0.0008 \mathrm{x}-0.0303, \mathrm{r}^{2}=0.9975$ ) for total phenols, and (equation: $\mathrm{y}=0.003 \mathrm{x}+0.0001, \mathrm{r}^{2}=$ 0.9981) for total flavonoids. The quantities of total phenols and flavonoids obtained are listed in Table-3, indicating that methanol extracts exhibited the highest values for both total phenols and flavonoids as compared with other solvent extracts: acetone, water, and dichloromethane.

The total phenols varied from 270.801 to $932.582 \mathrm{GAE} \mathrm{mg/g}$ of the extract powder, and the solvents extraction in the range methanol $>$ acetone $>$ water $>$ dichloromethane. For flavonoids contents, it varied 
RASĀYAN J. Chem.

Vol. 13 | No. 1 |423 - 433| January - March | 2020

from 160 to $345.56 \mathrm{QE} \mathrm{mg/g}$ of the extract powder, and the solvents extraction in the range methanol $>$ water $>$ acetone $>$ dichloromethane, both total phenols and flavonoids under ultrasonication method exhibited similar activities. The same trend was also observed by the maceration method (Table-5). Methanol and acetone polar extractants exhibited the best actions in all solvents systems as compared with other extracts. It could be due to the polarity nature of the constituents present in the extractant; furthermore, most antioxidant constituents are polar secondary metabolites phenolic compounds particularly flavonoids. ${ }^{13,14,16,25}$

Consequently, comparing water extracts amongst the three methods of extraction: ultrasonication, maceration and decoction methods, the decoction method of extraction was found to be more effective as compared with maceration and ultrasonication. The trend of water solvent for total phenol contents can be ranged as: (decoction; 574.89) > (ultrasonication; 434.06) > (maceration; 434.060) $\mathrm{GAE} \mathrm{mg} / \mathrm{g}$ and flavonoids $(345.23>344.23>344.20)$ QEmg/g for decoction, ultrasonic and maceration methods respectively (Table-5). The trends observed in this study are in agreement with the reports of Tiwari et al. ${ }^{27}$ and Velicković et al. ${ }^{23}$, indicating the significance of solvents and plant relations. Plants used for traditional remedies are well known to contain a number of compounds such as phenols and flavonoids useful for treating chronic and acute infectious disease ${ }^{25,28-30}$, possess anti-inflammatory, antioxidant and anticancer properties. ${ }^{25,30}$ Phenolics are recognized to be effective against viruses, bacteria, and fungi. ${ }^{11,29,30}$ Numerous reports have revealed that higher antioxidant action connected with medicinal plants are ascribed to the phenolic constituents. ${ }^{32}$

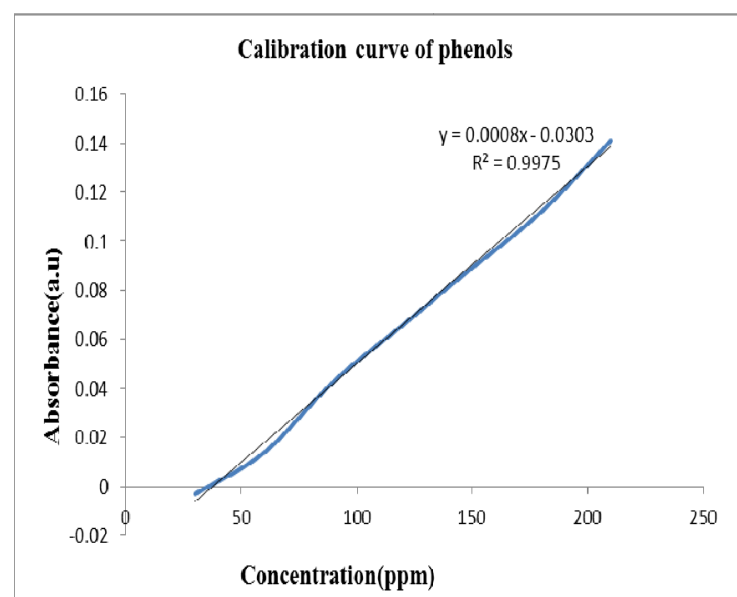

(A)

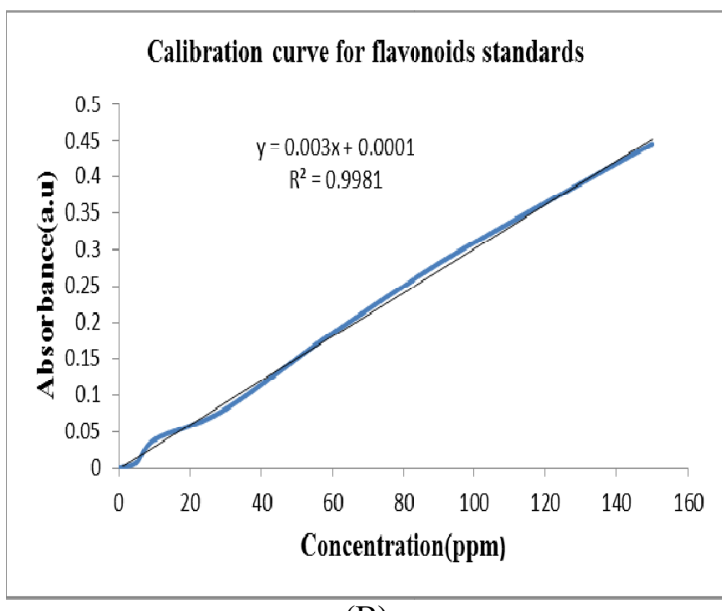

(B)

Fig.-1: (A) Calibration Curve of Phenolic Contents Articulated as mg of Gallic Acid g of the Dry Sample; (B) Calibration Curve of Total Flavonoids Expressed as Quercetin g of Dry Sample.

\section{Investigation of DPPH Radical Scavenging Activity By Plant Extracts}

The radical scavenging activity of the different Teedia Lucida root extracts via two methods of extraction was investigated, and quercetin utilized as a positive control, as indicated in Table-6. The results revealed that the extracts of polar solvent like acetone exhibited good radical scavenging activities with both ultrasonication method $(8.11,12.96,28.66,33.89$, and $42.81 \%)$ and maceration method $(2.08,7.29$, $10.08,13.11$, and $14.96 \%$ ) as compared to polar methanol extracts by ultrasonication and maceration methods ranging from 1.27-39.09 \% with respect to different concentrations investigated. However, dichloromethane (DCM) extracts by ultrasonication method showed significant better DPPH radical inhibition comparable to the standard quercetin used as a positive control, and higher activity in comparison with a polar solvent of acetone and methanol extracts ${ }^{26}$ (Fig.-2). These results demonstrated that DCM holds better inhibition effectiveness tailed by methanol, then acetone. In Fig.-2, the rate of inhibition of quercetin and the solvent extract increases as the concentration increases (dose-dependent manner), with the DCM extracts from the ultrasonication method possessing inhibition above the \% RSA of the control (quercetin). It is interesting to note that at concentrations of 0.8 and $1.0 \mathrm{mg} / 1, \mathrm{DCM}$ extract by ultrasonication was found to be a good DPPH inhibitors than the control. In overall, the extracts 
RASĀYAN J. Chem.

Vol. 13 | No. 1 |423 - 433| January - March | 2020

obtained by ultrasonication method exhibited better DPPH radical scavenging activities than the extracts by the maceration method. The order of the mean antioxidant activities of the test samples can be ranked: Quercetin $>$ DCM-ultra $>$ ACE-ultra $>$ MET-ultra $>$ DCM-mace $>$ ACE-mace $>$ MET-mace (Table-6).

Table-5: The Total Phenols and Flavonoids Contents in Teedia Lucida roots of Different Extraction Methods

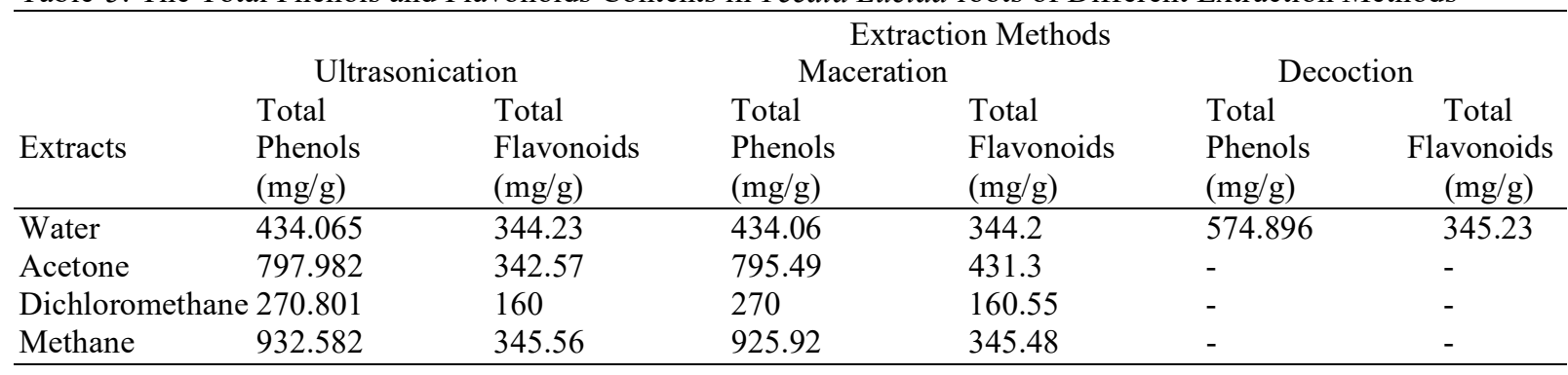

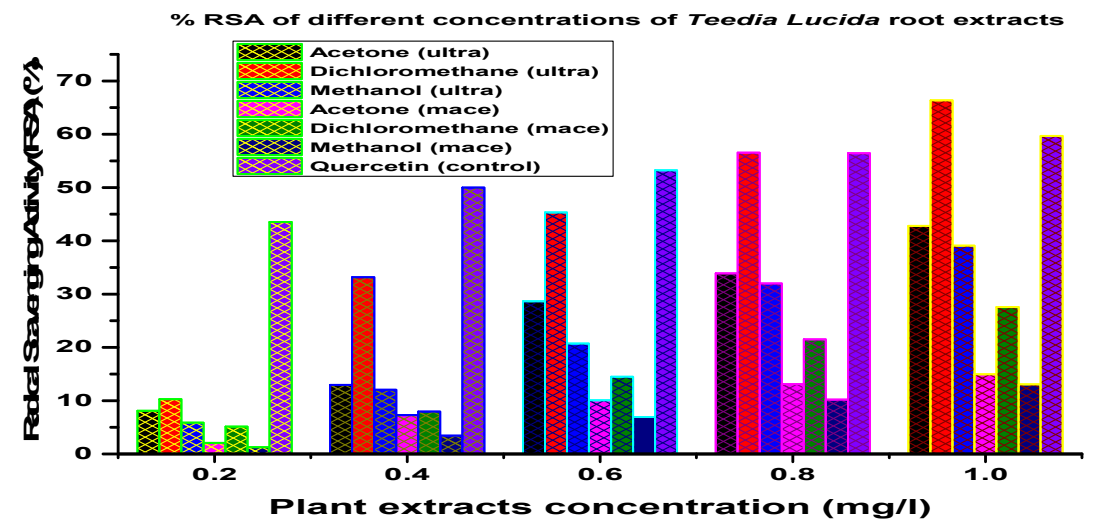

Fig.-2: Percentage Radical Scavenging Activity of Teedia Lucida Root Extracts on DPPH Radicals [Note: UltraUltrasonication; mace- Maceration]

Table-6: DPPH Radical Scavenging Activity of Different Teedia Lucida Root Extracts

\begin{tabular}{cccccccc}
\hline $\begin{array}{c}\text { Concentration } \\
(\mathrm{mg} / \mathrm{l})\end{array}$ & ACE-ultra & DCM-ultra & MET-ultra & ACE-mace & $\begin{array}{c}\text { Antioxidant Activity For RSC }(\%) \\
\text { mace }\end{array}$ & $\begin{array}{c}\text { MET- } \\
\text { mace }\end{array}$ & $\begin{array}{c}\text { Quercetin } \\
\text { (Control) }\end{array}$ \\
0.2 & 8.11 & 10.28 & 5.88 & 2.08 & 5.14 & 1.27 & 43.55 \\
0.4 & 12.96 & 33.18 & 12.04 & 7.29 & 7.944 & 3.44 & 50.00 \\
0.6 & 28.66 & 45.33 & 20.72 & 10.08 & 14.49 & 6.93 & 53.23 \\
0.8 & 33.89 & 56.54 & 32.00 & 13.11 & 21.5 & 10.21 & 56.45 \\
1.0 & 42.81 & 66.36 & 39.09 & 14.96 & 27.58 & 13.07 & 59.68 \\
\hline
\end{tabular}

Methanol (ultra)- MET-ultra; Methanol (mace)- MET-mace; Acetone (ultra)- ACE-ultra; Acetone (mace)- ACE-mace; Dichloromethane (ultra)- DCM-ultra; Dichloromethane (mace)- DCM-mace; ultra- Ultrasonication; mace- Maceration.

Determination of the Antibacterial Activity of Teedia Lucida Extracts Against $S$. sonnei and $S$. aureus Micro-organisms

Following the total phenol and flavonoid contents and good radical scavenging potentials of the different solvent extracts of Teedia Lucida, it became imperative to evaluate the various solvent extracts microbicidal action. The antibacterial activity of acetone, methanol and dichloromethane extracts from two different extract methods of $T$. Lucida root was studied against two bacterial isolates using microplate dilution method (Table-7). Previous reports have revealed that plant extracts exhibiting good antioxidant activity also show antimicrobial activity owing to the total phenol and flavonoids content in the various solvent extracts. ${ }^{6,11,13,14,23,27,29,30}$ Two micro-organisms used are Shigella Sonnei (Gram-negative) and Staphylococcus aureus (Gram-positive), while neomycin served as the positive control.

Table-7 showed that methanol extracts $(0.3195$ and $0.639 \mu \mathrm{g} / \mathrm{ml})$ from ultrasonication methods possess better antimicrobial activity than acetone extract against the two studies strains: S. Sonnei and S. aureus 
RASĀYAN J. Chem.

Vol. 13 | No. 1 |423 - 433| January - March | 2020

(Fig.-3). However, acetone extract $(0.7953$ and $0.8 \mu \mathrm{g} / \mathrm{ml})$ by the maceration method exhibited higher antibacterial activity against $S$. Sonnei and $S$. aureus strains than methanol extract by maceration method. This observation recommends that the investigated fractions possess a broad spectrum of antimicrobial action. Plant extracts possessing low MIC values could be a better frontier of bioactive compounds with antimicrobial strength. ${ }^{11,13,14,23,25}$ The results indicated low MIC of the solvent extracts and the order follows: methanol $>$ acetone $>$ dichloromethane by ultrasonication method, while with the maceration method, acetone $>$ methanol $>$ dichloromethane against $S$. sonnei and $S$. aureus strains. However, neomycin (control) exhibited better activity than the plants extracts with lower MIC values of 0.016 and $0.063 \mu \mathrm{g} / \mathrm{ml}$ against $S$. sonnei and $S$. aureus, respectively. The results showed that $S$. aureus is more resistant towards antimicrobial agents (the extracts), this phenomenon could be attributed to the thickness of bacteria cell wall formed by repeating units of peptidoglycan layers. This formation resulted in a thick membrane that resists the permeation of antimicrobial agents like phenolic compounds present in plants. ${ }^{33}$

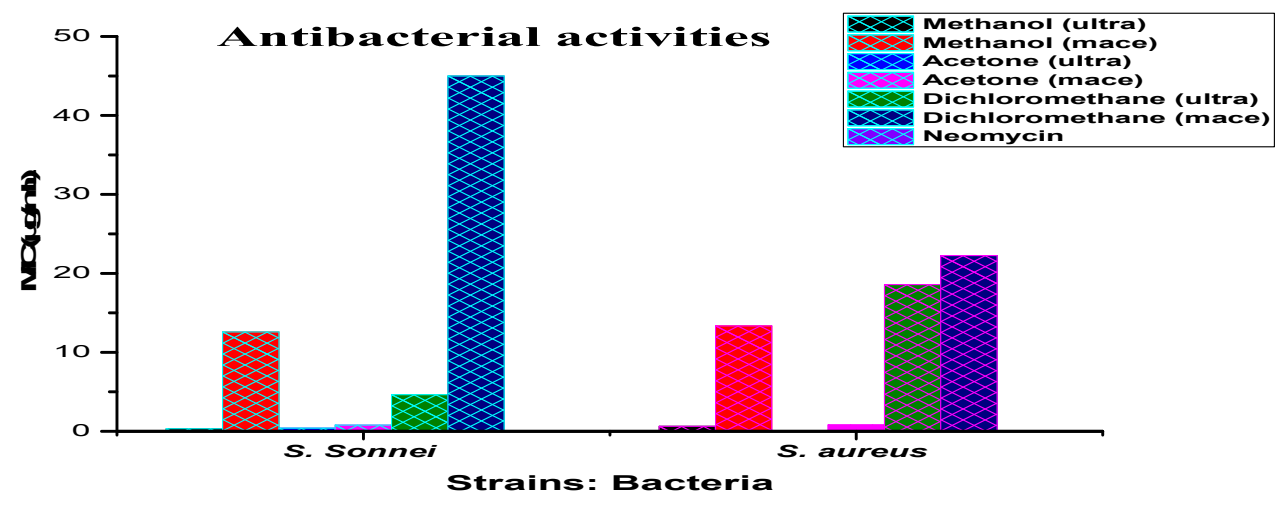

Note: Ultra- Ultrasonication; mace- Maceration

Fig.-3: Antibacterial Activities of Teedia Lucida Root Extracts Against S. Sonnei and S. aureus.

Table-7: Minimum Inhibitory Concentrations of Plant Extracts against S. sonnei and S. aureus

\begin{tabular}{lll}
\hline Extract & Pathogens & $\begin{array}{l}\text { MIC } \\
(\mu \mathrm{g} / \mathrm{ml})\end{array}$ \\
\hline $\begin{array}{l}\text { Methanol ultra } \\
\text { Methanol mace }\end{array}$ & Shigella Sonnei & 0.3195 \\
& & 12.58 \\
Acetone ultra & Shigella Sonnei & 0.3968 \\
Acetone mace & & 0.7953 \\
Dichloromethane ultra & Shigella Sonnei & 4.644 \\
Dichloromethane mace & & 45 \\
Methanol ultra & Staphylococcus aureus & 0.630 \\
Methanol mace & & 13.35 \\
Acetone ultra & Staphylococcus aureus & 0.792 \\
Acetone mace & & 0.8 \\
Dichloromethane ultra & & 18.58 \\
Dichloromethane mace & Staphylococcus aureus & 22.25 \\
Neomycin & & 0.016 \\
(Positive control) & Shigella Sonnei & \\
Neomycin & & 0.063 \\
(Positive control) & Staphylococcus aureus & \\
\hline
\end{tabular}

ultra- Ultrasonication; mace- Maceration 
RASĀYAN J. Chem.

Vol. 13 | No. 1 |423 - 433| January - March | 2020

\section{CONCLUSION}

The study has shown that secondary metabolites present in different solvent extracts of Teedia Lucida root possess antioxidant and antibacterial activity, which explains the traditional use of the plant for inflammatory infections brought about by oxidants in the human metabolism. The study also provides insight into the use of T. Lucida plant extracts by fever or cold patients. It revealed the different yields of extraction methods such as maceration, decoction, and ultrasonication; however, these methods can be limited about the secondary metabolites targeted. Ultrasonication and decoction shouldered to be a more effective extraction method than maceration (ultrasonication $>$ decoction $>$ maceration). The antimicrobial and antioxidants activities of the solvent extracts was verified by the trend in total phenols (methanol $>$ acetone $>$ water $>$ dichloromethane), and flavonoids (methanol $>$ acetone $>$ water $>$ dichloromethane). The microbicidal activity of the methanol extract possesses higher MIC than acetone extract via ultrasonication method against $S$. sonnei and $S$. aureus organisms respectively, while the MIC for dichloromethane extract was higher than that of methanol and acetone by both methods of extractions. The mechanistic activity obtained from the analyses justifies the use of this plant root part in folk medicine for the treatment of infections. Therefore, this study provided a lead that can be further utilized for assessing other test models for different diseases by T. Lucida root parts. Consequently, supplementary studies are underway towards isolating the bio-active compounds from the extracts and perform other pharmacological test such as anti-cancer, anti-diabetic, and anti-inflammatory.

\section{ACKNOWLEDGMENT}

The authors are grateful for the financial support of Directorate of Research, Vaal University of Technology, Vanderbijlpark Campus and Institute of Traditional Knowledge and Traditional Medicine, Vaal University of Technology Southern Gauteng Science and Technology Park, Sebokeng, South Africa.

\section{REFERENCES}

1. N.S. Ncube, A.J. Afolayan, A.L. Okoh, African Journal of Biotechnology, 7(12), 179 (2008), DOI: 10.5897/AJB07.613

2. C. Lemus, G. Raphael, E.N. Ellong, W. Tian, M. Lecso-Bornet, S. Adenet, K. Rochefort, S. Michel, H. Dufat, Phytochemistry Letters, 13, 194 (2015), DOI: 10.1016/j.phytol.2015.06.013

3. M. Stan, A. Popa, D. Toloman, T.D. Silipas, D.C. Vodnar, Acta Metallurgica Sinica (English Letters), 29(3), 228 (2016), DOI: 10.1007/s40195-016-0380-7

4. G.A. Otunola, A.J. Afolayan, E.O. Ajayi, S.W. Odeyemi, Pharmacognosy Magazine, 13(Suppl 2), S201 (2017), DOI: $10.4103 / \mathrm{pm} . \mathrm{pm} \_430 \_16$

5. S. Hosseinzadeh, A. Jafarikukhdan, A. Hosseini, R. Armand, International Journal of Clinical Medicine, 6, 635 (2015), DOI: 10.4236/ijcm.2015.69084

6. F.M. Mtunzi, I.P. Ejidike, T. Matamela, E.D. Dikio, M.J. Klink, International Journal of Pharmacognosy and Phytochemical Research, 9(8), 1090 (2017), DOI: 10.25258/phyto.v9i08.9616

7. M.O. Malpani, P.R. Rajput, K.V. Chinchole, S.S. Kapse, K.S. Ambarkar, Rasayan Journal of Chemistry, 12(4), 1901 (2019), DOI: 10.31788/RJC.2019.1245447

8. T. Hailu, M. Endris, A. Kaleab, G.M. Tsige, Journal of Ethnopharmacology, 100(1-2), 169 (2005), DOI: $10.1016 /$ j.jep.2005.02.031

9. M. Masullo, P. Montoro, A. Mari, C. Pizza, S. Piacente. Journal of Pharmaceutical and Biomedical Analysis, 113, 189 (2015), DOI: 10.1016/j.jpba.2015.03.020

10. D. Millar, T. Agana, A.N. Beyuo, Global Journal of Agricultural Economics, Extension and Rural Development, 3(10), 338 (2015).

11. D. Millar, F.D. Yelsang, International Journal of Advanced Research, 4(8), 1192(2016), DOI: 10.21474/IJAR01/1321

12. M.P. Tshisikhawe, M.W. Van Rooyen, Journal of Medicinal Plants Research, 6(46), 5748 (2012), DOI: $10.5897 /$ JMPR12.1274

13. A. Batta, International Journal of Research in Medical Sciences, 2(1), 20(2016), DOI: 1.15/ijcrms2016-2-1-3

14. P.C. Chikezie, C.O. Ibegbulem, F.N. Mbagwu, Research Journal of Phytochemistry, 9(3), 88(2015), DOI: $10.3923 /$ rjphyto.2015.88.115 
15. C.N. Fokunang, V. Ndikum, O.Y. Tabi, R.B. Jiofack, B. Ngameni, N.M. Guedje, E.A. TembeFokunang, P. Tomkins, S. Barkwan, F. Kechia, E. Asongalem, J. Ngoupayou, N.J. Torimiro, K.H. Gonsu, V. Sielinou, B.T. Ngadjui, F. Angwafor III, A. Nkongmeneck, O.M. Abena, J. Ngogang, T. Asonganyi, V. Colizzi, J. Lohoue, Kamsu-Kom, African Journal of Traditional, Complementary and Alternative Medicines, 8(3), 284 (2011), DOI: 10.4314/ajtcam.v8i3.65276

16. M.P. Kähkönen, A.I. Hopia, H.J. Vuorela, J.P. Rauha, K. Pihlaja, T.S. Kujala, M. Heinonen, Journal of Agricultural and Food Chemistry, 47(10), 3954 (1999), DOI: 10.1021/j99901461

17. N. Rastakhiz, F. Khosravi, S.S.S. Jafari Olia, B. Iranmanesh, International Journal of Life Sciences, 9(5), 122 (2015), DOI: 10.3126/ijls.v9i5.12712

18. B. Lapornik, M. Prosek, A.G. Wondra, Journal of Food Engineering, 71(2), 214 (2005), DOI: 10.1016/j.jfoodeng.2004.10.036

19. A. Mokrani, K. Madani, Separation and Purification Technology, 162, 68 (2016), DOI: 10.1016/j.seppur.2016.01.043

20. P. Lim, S. Pang, M. Yusoff, J. Gimbun, Asia Proceedings of Social Sciences, 2(1), 14 (2018), DOI: 10.31580/apss.v2i1.271

21. P. Masoko, D.M. Makgapeetja, BMC Complementary and Alternative Medicine, 15, 409(2015), DOI: 10.1186/s12906-015-0941-8

22. S. Sasidharan, Y. Chen, D. Saravanan, K.M. Sundram, L.Y. Latha, African Journal of Traditional, Complementary and Alternative Medicines, 8(1), 1 (2011).

23. J.M. Velicković, D.S. Dimitrijević, S.S. Mitić, M.N. Mitić, D.A. Kostić, Advanced Technologies, 3(2), 46 (2014).

24. G. Bbosa, N. Mwebaza, J. Odda, D. Kyegombe, M. Ntale, Health, 6(5), 410(2014), DOI: 10.4236/health.2014.65059

25. F.M. Mtunzi, I.P. Ejidike, I. Ledwaba, A. Ahmed, V.E. Pakade, M.J. Klink, S.J. Modise, Asian Pacific Journal of Tropical Medicine, 10, 670 (2017), DOI: 10.1016/j.apjtm.2017.07.007

26. M. Vinatoru, T.J. Mason, I.C. Calinescu, Trac- Trends in Analytical Chemistry, 97, 159 (2017), DOI: 10.1016/j.trac.2017.09.002

27. P. Tiwari, B. Kumar, M. Kaur, G. Kaur, H. Kaur, Internationale Pharmacentica Sciencia, 1(1), 98 (2011).

28. Z. Salimi, A. Eskandary, R. Headari, V. Nejati, M. Moradi, Z. Kalhori, Indian Journal of Physiology and Pharmacology, 59(1), 87 (2015).

29. R. Gomez-Flores, Y. Gracia-Vásquez, M.G. Alanís-Guzmán, P. Tamez-Guerra, R. Tamez-Guerra, G. García-Díaz, E. Monreal-Cuevas, C. Rodríguez-Padilla, Medicinal Plants, 1(1), 11(2009), DOI: 10.5958/j.0975-4261.1.1.002

30. K.H. L. Singh, G.C. Bag, International Journal of PharmTech Research, 5(4), 1516(2013).

31. J.C. Taganna, J.P. Quanico, R.M.G. Perono, E.C. Amor, W.L. Rivera, Journal of Ethnopharmacology, 134(3), 865 (2011), DOI: 10.1016/j.jep.2011.01.028

32. T. Lokesh, B. Sarada, K. Swarnalatha, M.A. Kareem, N.C.H. Varadacharyulu. International Journal of Pharmaceutical Sciences and Research, 7(9), 3857(2016), DOI: 10.13040/IJPSR.09758232.7(9).3857-64

33. K. Das, R.K.S. Tiwari, D. Shrivastava D, Journal of Medicinal Plants Research, 4(2), 104(2010), DOI: $10.5897 / J M P R 09.030$

[RJC-5594/2019] 